\title{
GC-MS and HPLC Analysis of Chlorophytum Borivilianum (Safed Musli) A Plant from Ayurveda- Herbal Viagra
}

\author{
Ruchi Vyas, Garima Sharma, Adya Chaturvedi, Devki and Rashmi Sisodia* \\ Department of Zoology, University of Rajasthan, Jaipur, India
}

Submission: June 03, 2020; Published: June 09, 2020

*Corresponding author: Rashmi Sisodia, Department of Zoology, University of Rajasthan, Jaipur 302004, India

\begin{abstract}
The objective of this study was to determine the photochemical content of Chlorophytum borivilianum by GC-MS analysis and HPLC. Chlorophytum borivilianum is an endangered medicinal plant having several phyto constituents, which makes it suitable for many therapeutic applications. GC-MS analysis was carried out on a Shimadzu GCMSQP2010 Ultra system. Methanol is used as a solvent. The injector temperature was $280^{\circ} \mathrm{C}$. The samples were injected in the split mode with split ratio 1 to 60 . Injection volume was $1 \mu$ l. A capillary column Rtx-5MS (5\% Diphenyl-95\% Dimethyl Polysiloxane), $30 \mathrm{~m}$ x $0.25 \mathrm{~mm}$ x $0.25 \mu \mathrm{m}$, was used. The carrier gas was helium with a constant flow of $1.00 \mathrm{ml} / \mathrm{min} . G C-$ MS analysis of drug led to the identification of 9 compounds viz., 5-methylhex-2-yl pentadecyl ester (23.69\%), 9,10-Anthracenedione (19.02\%), Phthalic acid (18.63\%) etc. High-performance liquid chromatography was conducted to enumerate active ingredient in the plant extracts. These analyses help us to understand the importance of various phyto chemicals and also open up new ways to exploit a particular plant for various therapeutic and restorative purposes.
\end{abstract}

Keywords: Chlorophytum borivilianum; Gas chromatography; Phthalic acid; HPLC

\section{Introduction}

Chlorophytum borivilianum belongs to family Liliaceae Which is an herb found in the tropical wet forests in peninsular India. It is commonly called as Musli or Safed Musli in Hindi language. In the Ayurvedic literature, Safed Musli is celebrated as a Divya Aushad with unparalleled medicinal properties and therapeutic applications. It is considered an elixir to increase the general body immunity and has been reported to possess several biological activities including antimicrobial, anti-inflammatory, antipyretic, hepato protective, antioxidant, hypolipidemic and anti-diabetic [1] thus also known as 'white gold' [2] Its aphrodisiac properties have proved very much useful for the people suffering from Erectile Dysfunction and to increase male potency, it is extensively used as herbal Viagra due to its peculiar and It has sperm atogenic property helps cure impotency as they are rich in glycosides [3] Safed Musli Which is also gaining increasing acceptance as a vitalizer and health-giving tonic, acurative for pre-natal and post-natal problems, a restorative for immunity-improvement. The recent discovery of Safed Musli as a natural and safe aphrodisiac agent has also opened up new channels of application and new demand for it. Safed Musli is a herb and is also an ideal aphrodisiac with no negative side-effects associated with chemical-based aphrodisiac.
Roots are claimed to be useful to treat oligospermia, pre- and postnatal symptoms, arthritis, diabetes and dysuria [4]. Itis a threatened species and named 'Chlorophytum' due to the white milky texture of its tubers after peeling. Since ages, tribal communities in India used Safed Musli for enhancing their virility and thus due to its overexploitation it has reached the rare status in nature. It is used for rheumatism and joint pains, increases lactation in feeding mothers, diarrhoea, dysentery, gonorrhoea, leucorrhea etc. Its root contains steroidal and triterpenoid saponins, sapogenins and fructans which act as therapeutic agents and play a vital role in many therapeutic applications. It is a rich source of over 25 alkaloids, vitamins, proteins, carbohydrates, steroids, saponins, potassium, calcium, magnesium, phenol, resins, mucilage, and polysaccharides and also contains a high quantity of simple sugars, mainly sucrose, glucose, fructose, galactose, mannose and xylose [5]. Steroidal saponins, polysaccharides, fructans and fructo oligosaccharides, Beta-sitosterol, stigmasterol, hecogenin and mucilage are major constituents of $C$. Borivilianum that act as therapeutic agents.The in vitro propagated roots were tested for the production of pharmaceutically important secondary metabolites stigmasterol and hecogenin. A maximum of 46.4 


\section{Global Journal of Reproductive Medicine}

$\mathrm{mg} / \mathrm{gDCW}$ of stigmasterol and $685 \mathrm{mg} / \mathrm{gDCW}$ of hecogenin was evident in these cultures [6]. Gas chromatography has a very wide field of applications. It is used is in the separation and analysis of multi-component mixtures such as essential oils, hydrocarbons and solvents. Intrinsically, with the use of the flame ionization detector and the electron capture detector (which have very high sensitivities) gas chromatography can quantitatively determine materials present at very low concentrations [7]. HPLC is ideally suited for the rapid processing of the multi component samples on both an analytical and preparative scale. Chemical separations can be accomplished using HPLC by utilizing the fact that certain compounds have different migration rates given a particular column and mobile phase [8].

\section{Materials and Methods}

\section{Preparation of plant extract}

The pure dried root powder of $C$. borivilianum was purchased commercially from Naturemed, Hyderabad, AP. Then plant root extract (CBE) was prepared by mixing $1-5 \%$ of plant root powder with deionized water in a $250 \mathrm{ml}$ of (Borosil, India) conical flask. The solution was boiled in a water bath and then incubated at 50$70^{\circ} \mathrm{C}$ for an hour followed by filtering from What man paper [9].

\section{GC MS analysis}

GC-MS analysis was carried out on a Shimadzu GCMSQP2010 Ultra system. Methanol was used as a solvent. The injector temperature was $280^{\circ} \mathrm{C}$. The samples were injected in the split mode with split ratio 1 to 60 . Injection volume was $1 \mu \mathrm{l}$. A capillary column Rtx-5MS (5\% Diphenyl-95\% Dimethyl Polysiloxane), $30 \mathrm{~m} \times 0.25 \mathrm{~mm} \times 0.25 \mu \mathrm{m}$, was used (Figure 1). The carrier gas was helium with a constant flow of $1.00 \mathrm{ml} / \mathrm{min}$.The oven temperature was as follows: initial temperature of $60^{\circ} \mathrm{C}$, held for $2 \mathrm{~min}$, increased to $10^{\circ} \mathrm{C} / \mathrm{min}$ up to $260^{\circ} \mathrm{C}$ and held for $10 \mathrm{~min}$. The MS ionization potential was $70 \mathrm{eV}$, and the temperatures were as follows: interface $260^{\circ} \mathrm{C}$, Ion source $280^{\circ} \mathrm{C}$. Mass scan range 40-550. GC-MS analysis of C. Bori vilianum root extract led to the identification of the following compounds (Table 1). Highperformance liquid chromatography (HPLC) is a versatile, robust, and widely used technique for the isolation of natural products [10] Currently, this technique is gaining popularity among various analytical techniques as the main choice for fingerprinting study for the quality control of herbal plants [11]. Natural products are frequently isolated following the evaluation of a relatively crude extract in a biological assay to fully characterize the active entity. The method followed for High-performance liquid chromatography was according to Kardani et al. [12] as published.

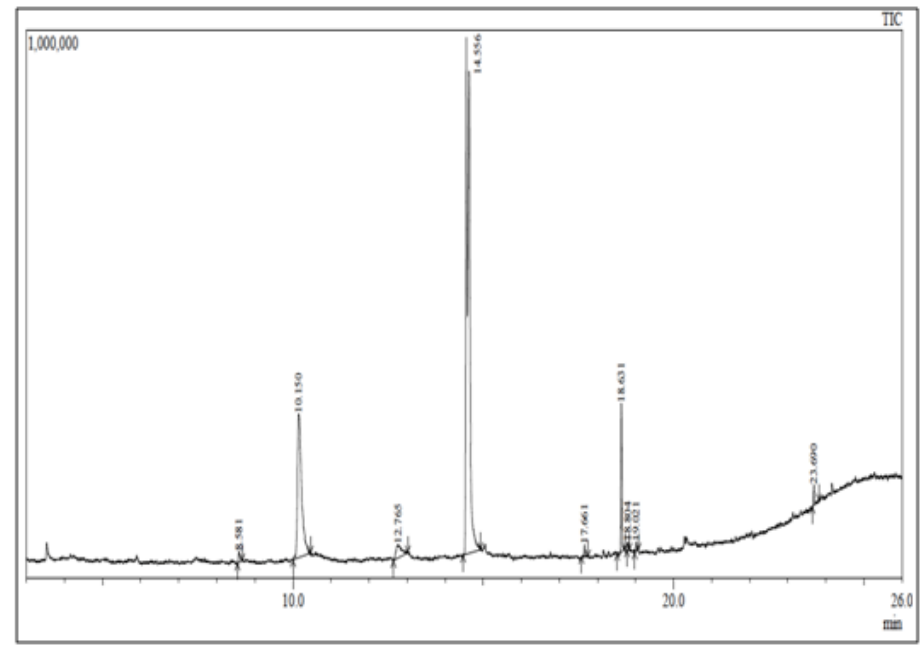

Figure 1: Chromatogram of $\mathrm{C}$ borivillianum showing 9 distinct peaks at various retention time.

Table 1: Phyto components identified in $C$ borivilianum.

\begin{tabular}{|c|c|c|}
\hline Peak & Retention Time & Name \\
\hline 1 & 8.58 & 4H-Pyran-4-one, 2,3-dihydro-3,5-dihydroxy-6-methyl \\
\hline 2 & 10.15 & Diethyl Phthalate \\
\hline 3 & 12.76 & 1,3-Propanediol, 2-(hydroxymethyl)-2-nitro-Isobutylglycerol \\
\hline 4 & 14.56 & Diethyl Phthalate \\
\hline
\end{tabular}




\begin{tabular}{|c|c|c|}
\hline 5 & 17.66 & Phthalic acid, butyl isopropyl ester \\
\hline 6 & 18.63 & Phthalic acid, butyl nonyl ester \\
\hline 7 & 18.81 & 2-Fluorenecarboxaldehyde \\
\hline 8 & 19.02 & 9, 10-Anthracenedione \\
\hline 9 & 23.69 & Phthalic acid, 5-methylhex-2-yl pentadecyl ester \\
\hline
\end{tabular}

\section{Analysis of active ingredients in plant extract}

HPLC was carried out for detection of active ingredients in aqueous extracts of $C$. borivilianum. Gallic acid was used as a standard marker in this experiment. A peak was observed at 3.08 min retention time (RT), with an area of $2.713 \mathrm{mAU}$, for standard Gallic acid. For the test sample, a $20-\mu$ l solution injected and ran for $10 \mathrm{~min}$ (Figure 2a-2j). Two prominent peaks were observed, among which one matched the RT of gallic acid ( $3.08 \mathrm{~min})$, whereas, another peak of greater concentration was observed at retention time $2.5 \mathrm{~min}$. Besides these two peaks, 6 small peaks were also observed at RT $1.8 \mathrm{~min}, 3.12 \mathrm{~min}, 4.7 \mathrm{~min}, 6 \mathrm{~min}, 6.8 \mathrm{~min}$ and 7.2 min. Considering injected sample without any contamination a total of 8 active compounds were present in the aqueous solution of $C$. borivilianum (Figure 3).

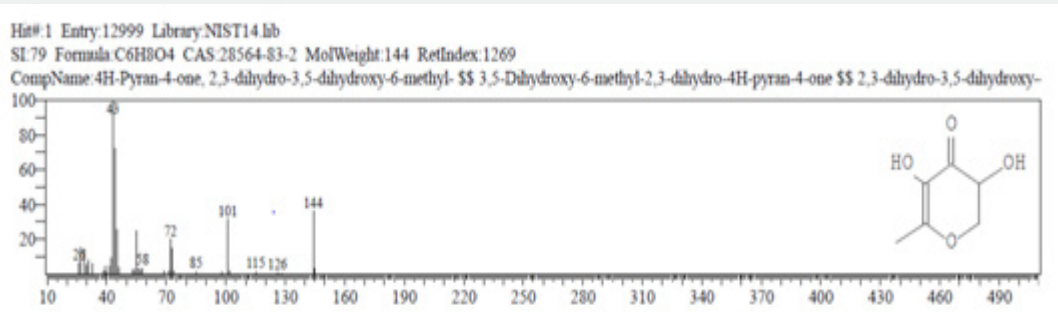

Figure 2a: List of identified compounds from C borivillianum are ascertained with NIST14 Library.

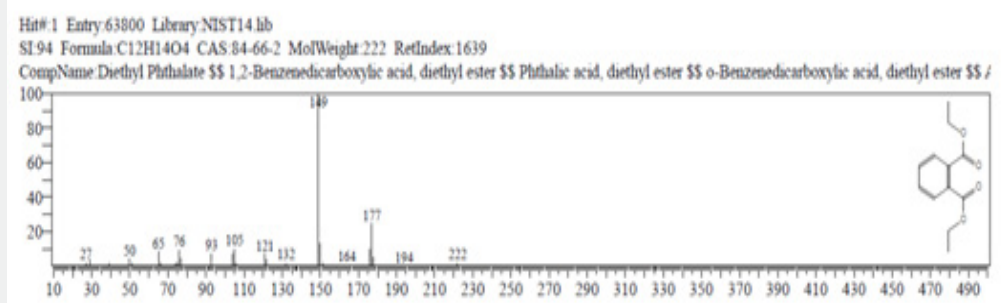

Figure 2b: List of identified compounds from C borivillianum were ascertained with NIST14 Library.

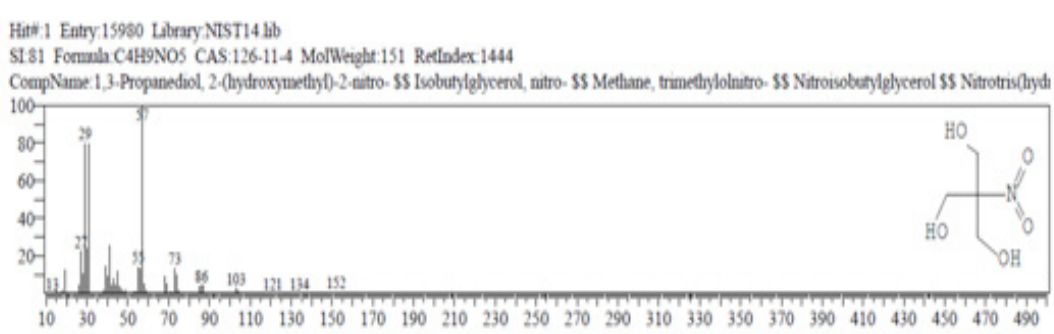

Figure 2c: List of identified compounds from C borivillianum are ascertained with NIST14 Library. 


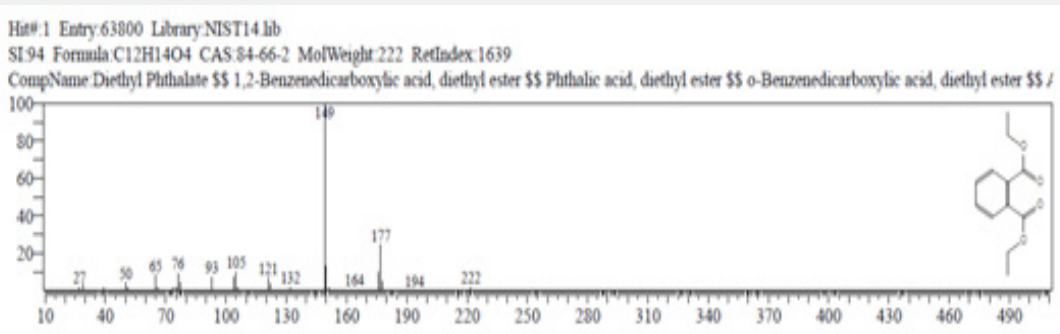

Figure 2d: List of identified compounds from C borivillianumm are ascertained with NIST14 Library.

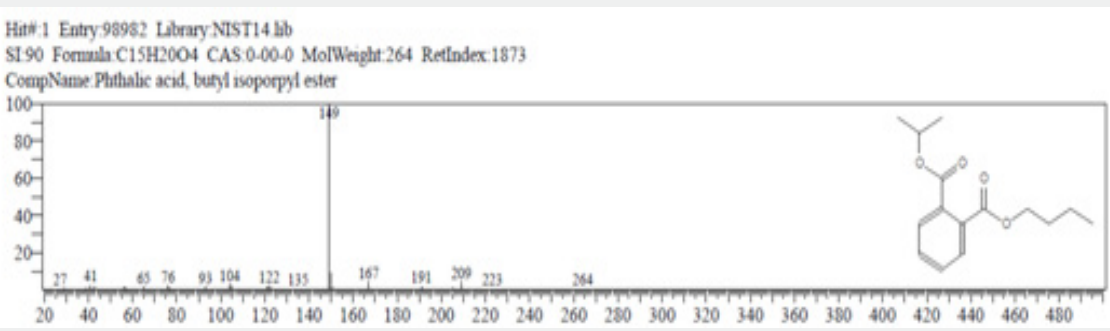

Figure 2e: List of identified compounds from C borivillianum are ascertained with NIST14 Library.

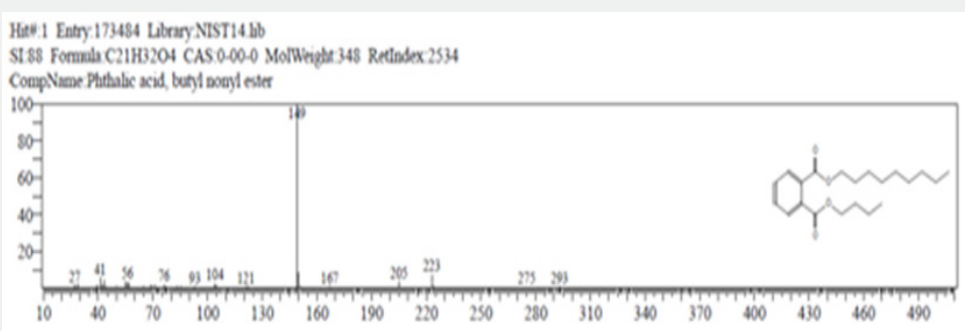

Figure 2f: List of identified compounds from C borivillianumare ascertained with NIST14 Library.

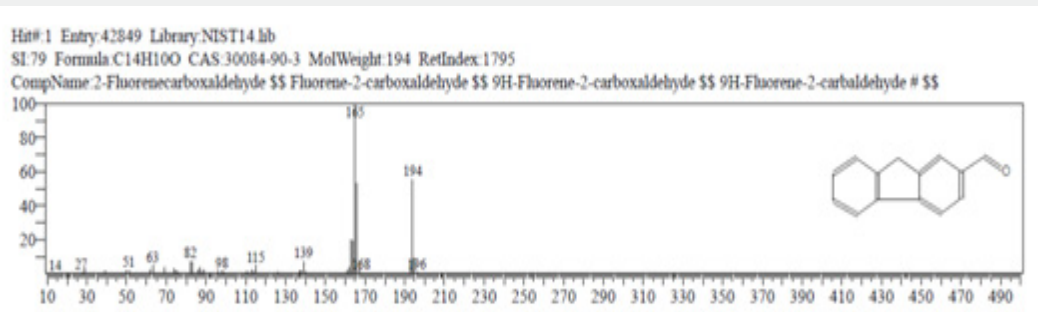

Figure 2g: List of identified compounds from C borivillianumare ascertained with NIST14 Library.

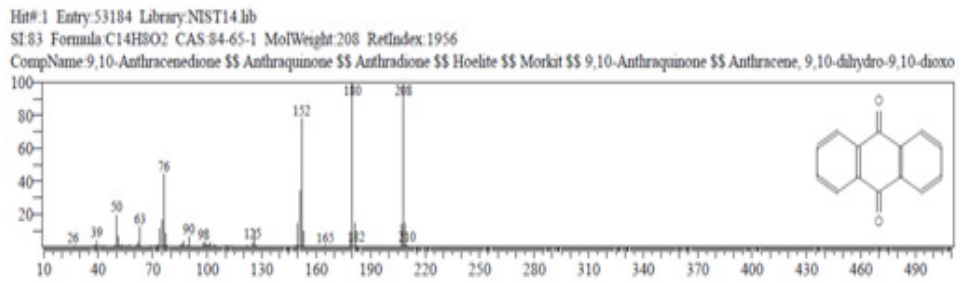

Figure $2 \mathrm{~h}$ : List of identified compounds from C borivillianum are ascertained with NIST14 Library. 


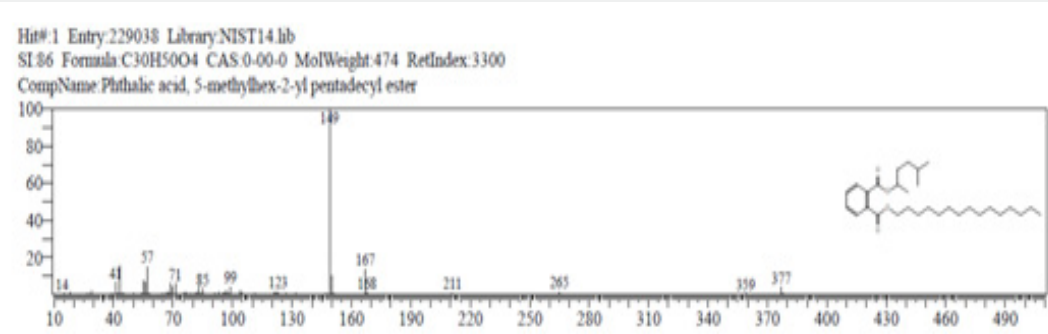

Figure 2j: List of identified compounds from C borivillianum are ascertained with NIST14 Library.

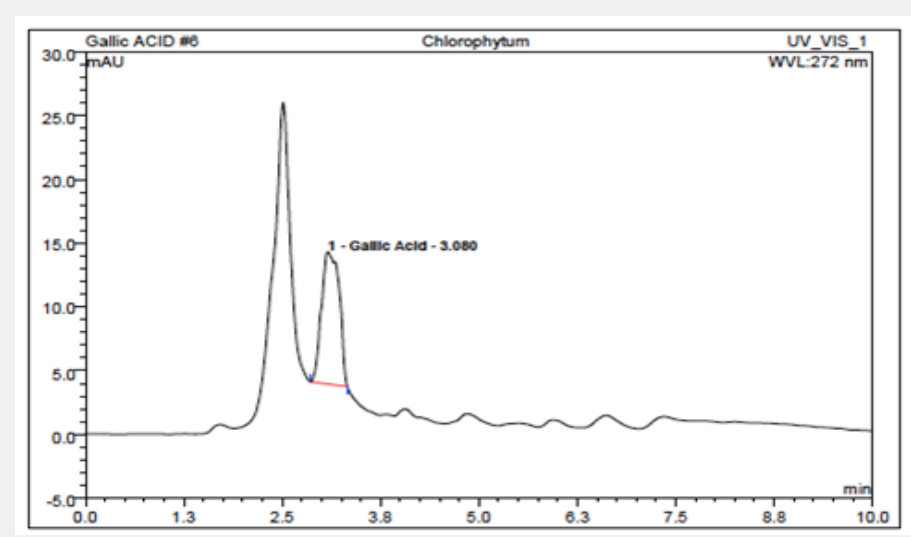

Figure 3: HPLC chromatogram of $C$ borivillianum root extract, showing eight distinct peaks at variable retention time.

\section{Results and Discussion}

The results of GC-MS analysis led to the identification of several compounds from the GC fractions of the extract of $C$. borivilianum. These compounds were identified through mass spectrometry attached with GC. The results of the GC-MS was interpreted by using the database of the National Institute of Standards and Technology (NIST) library having more than 2,00,000 patterns. The GC-MS spectrum of the unknown constituent was then compared with the known components stored in the NIST-14 library. The results of the present study are tabulated in Table 1. The identified constituents from the root extract of $C$. borivilianum like a saponin glycoside 4 H-Pyran4-one, 2,3-dihydro-3,5-dihydroxy-6-methyl possess antifungal activity $[13,14] 9,10$-Anthracenedione possess anticancer activity [15], butyl isopropyl ester as an antimicrobial agent [16] Diethyl phthalate (DEP) is known as a colourless liquid which has a slight aromatic odour. It is used in the various applications such as sprays of insecticides, as an ingredient in coatings of aspirin, cosmetics, food and pharmaceutical packaging, preparation of skincare products [17,18] 2-fluorenecarboxaldehyde have antioxidant activity [19] 5-methylhex-2-yl pentadecyl ester shows antimicrobial activity [20].

\section{Conclusion}

The result of GC-MS and HPLC indicated the presence of vital bioactive phyto constituents belonging to various groups of alkaloids, glycosides, steroids, etc. Based on the results it can be concluded that $C$. borivilianum is the plant with potential therapeutic and nutritional importance thuscould be used as a natural source of antioxidants and its regular consumption in diet could provide health benefits to humans by the protection against oxidative stress.

\section{Acknowledgement}

The authors are thankful to the Department of Zoology, Centre for Advanced Studies, University of Rajasthan, Jaipur for providing necessary infrastructure \& facility. We are also thankful DSTInspire fellowship program for continuous funding.

\section{References}

1. Khanam Z, Singh O, Singh R, Bhat IUH (2013) Safed Musli (Chlorophytum borivilianum): A review of its botany, ethnopharmacology and phytochemistry. J Ethnopharmacol 150(2): 421-441.

2. Lokhande R, Singare P, Andhale M (2010) Study on mineral content of some Ayurvedic Indian medicinal plants by instrumental neutron activation analysis and AAS techniques. Health Sci J 4(3): 157-168.

3. Thakur M, Thompson D, Connellan P, Deseo MA, Morris C, et al.(2011) Improvement of penile erection, sperm count and seminal fructose levels in vivo and nitric oxide release in vitro by ayurvedic herbs. Andrologia 43(4): 273-277.

4. Sharma P, Chandrul KK (2017) Chlorophytum borivilianum (Safed Musli): A vital herbal drug. Int J Pharm Med Res 5: 401-411. 
5. Deore SL, Khadabadi SS (2010) Isolation and characterization of phytoconstituents from Chlorophytum borivilianum. Pharmacognosy Research 2(6): 343.

6. Thakur GS, Bag M, Sanodiya BS, Debnath M, Zacharia A, et al. (2009) Chlorophytum borivilianum: white gold for biopharmaceuticals and nutraceuticals. Current Pharmaceutical Biotechnology 10(7): 650-666.

7. Bathoju G, Giri A (2012) Production of medicinally important secondary metabolites (stigmasterol and hecogenin) from root cultures of Chlorophytum borivilianum (Safed Musli). Recent Research in Science and Technology 4(5).

8. Al Rubaye AF, Hameed IH, Kadhim MJ (2017) A review: uses of gas chromatography-mass spectrometry (GC-MS) technique for analysis of bioactive natural compounds of some plants. International Journal of Toxicological and Pharmacological Research 9(1): 81-85.

9. Krishnan V (2019) Estimation of bioactive compounds using HPLC. Biochemistry: A Practical Manual p. 36.

10. Cannell RJP (1998) Natural Products Isolation. Human Press Inc. New Jersey, USA, pp. 165-208.

11. Fan XH, Cheng YY, Ye ZL, Lin RC, Qian ZZ (2006) Multiple chromatographic fingerprinting and its application to the quality control of herbal medicines. Anal Chim Acta 555: 217-224.

12. Kardani GS, Heydarnejad J, Zakiaghl M, Mehrvar M, Kraberger S (2013) Diversity of beet curly top Iran virus isolated from different hosts in Iran. Virus Genes 46(3): 571-575.

13. Teoh YP, Don MM (2016) Extraction Of 4H-Pyran-4-One, 2, 3-Dihydro6-Methyl-, an alternative antifungal agent, from Schizophyllum commune: optimization and kinetic study. Borneo Science 37(1): 1-22.

14. Wongsadee T, Vatanyoopaisarn S, Thumthanaruk B, Puttanlek C, Uttapap D, et al. (2019) Comparison of 2-acetyl-1-pyrroline production between Aspergillus awamori and Aspergillus oryzae. In IOP Conference Series: Earth and Environmental Science. IOP Publishing 346(1): p. 012042.

15. Stasevych M, Zvarych V, Lunin V, Deniz NG, Gokmen Z (2017) Computeraided prediction and cytotoxicity evaluation of dithiocarbamates of 9, 10-anthracenedione as new anticancer agents. SAR and QSAR in Environmental Research 28(5): 355-366.

16. Güzel Bayülken D, Ayaz Tüylü B (2019) In vitro genotoxic and cytotoxic effects of some paraben esters on human peripheral lymphocytes. Drug and chemical toxicology 42(4): 386-393.

17. Kalpana G, Aushev VN, Fabiana M, Falcioni L, Simona P et al. (2020) Gene expression profiles for low-dose exposure to diethyl phthalate in rodents and humans: a translational study with implications for breast carcinogenesis. Scientific Reports Nature Publisher Group. 10(1).

18. DA Husein, HA, Albadry MA (2019) In Vitro Antimicrobial Activity and GC-MS Analysis of Crude Aqueous Methanolic Extract Produced from Leaves of Eucalyptus species. University of Thi-Qar Journal of Medicine 17(1): 54-69.

19. Karimi E, Mehrabanjoubani P, Homayouni Tabrizi M, Abdolzadeh A, Soltani M (2018) Phytochemical evaluation, antioxidant properties and antibacterial activity of Iranian medicinal herb Galanthus Transcaucasus Fomin. Journal of Food Measurement and Characterization 12(1), 433440.

20. Gernon MD, Dowling CM (2008) US Patent Application.

\section{Your next submission with Juniper Publishers will reach you the below assets}

- Quality Editorial service

- Swift Peer Review

- Reprints availability

- E-prints Service

- Manuscript Podcast for convenient understanding

- Global attainment for your research

- Manuscript accessibility in different formats

( Pdf, E-pub, Full Text, Audio)

- Unceasing customer service

Track the below URL for one-step submission https://juniperpublishers.com/online-submission.php 